\title{
LAS DESVIACIONES DE PÁRMENO O LA CAÍDA DE UN ÁNGEL ${ }^{1}$
}

\author{
Carlos Heusch \\ Université de Montpellier III
}

Cualquier estudio de los personajes de Celestina demuestra hasta qué extremo éstos están expuestos a variar. Alan Deyermond opina que la transformación que sufren a consecuencia de la acción es una de las innovaciones más notables de Rojas. ${ }^{2}$ En cambio, P. Russell ${ }^{3}$ considera que Rojas construye a sus personajes con una dosis importante de improvisación y fluctuación, lo que explicaría las desviaciones sufridas por unos y otros.

Si bien las desviaciones parecen acompañar la configuración de todos los personajes de Celestina, no cabe la menor duda de que, para uno de ellos, se trata de una característica fundamental. Éste es Pármeno, cuya trayectoria, desde el primer auto hasta el decimotercero, en el que se anuncia su muerte, conoce el cambio más radical. No se trata, en efecto, de una evolución, sino de una total inversión, ya que el criado, ejemplar en un principio, sufre una caída en el mal tan brutal, que merece la pena observarla de cerca.

Esta conversión al mal de un adolescente está descrita con minucia y escrupulosamente dotada de significado. El objeto de este trabajo es tratar de entender mejor esa focalización, consciente o inconsciente, en la caída de Pármeno, par la cual me basaré en un análisis de las variadas áreas semánticas y simbólicas que atraviesan las desviaciones del personaje.

Como bien se sabe, el tema de la caída es uno de los elementos que estructuran la obra de Rojas. Su eficacia, en el campo de la significación, reside en la estrecha relación que tiene con el de la Fortuna. No es casual, por consiguiente, que Pármeno, Sempronio o Calixto y Melibea sufran una caída fatal, en lo recto como en lo figurado. En el caso preciso de Pármeno, esa caída, antes de quitarle la vida, lo lleva de la virtud al vicio, del perfecto bien al mal más absoluto, por medio de una pérdida de la inocencia original. De ahí que el personaje aparezca como una imagen prototípica, conforme al imaginario judeo- 
cristiano, de esa clase de caída, de esa desviación fundamental: la imagen del ángel que, en su caída, se transforma en diablo. ${ }^{4}$

Conviene preguntarse, más allá de la mera fórmula, si, en la configuración inicial del personaje de Pármeno, existen elementos significativos capaces de crear una semiótica del ángel susceptible de sustentar esa interpretación de la desviación. Efectivamente, el texto no carece de elementos que connoten el angelismo. Está, de entrada, la imagen inicial de una "angélica inocencia," totalmente ajena al vicio, que se expresa por medio de la poca edad del personaje. Pármeno aparece como un niño (se insiste en la palabra mozo), ${ }^{5}$ lo que induce a Celestina a llamarlo angelico ${ }^{6}$ en una frase repleta de diminutivos. La expresión es usual, pero llama la atención aquí porque pone de manifiesto la asociación presente en el inconsciente colectivo (que aparece en la iconografía) entre el niño y el ángel, a través del concepto de inocencia, ${ }^{7}$ pero sobre todo porque recae sobre este personaje, en concreto. Claro está que, cuando Celestina llama a Pármeno angélico, lo hace en un contexto de seducción muy peculiar. Sin embargo, conviene quedarse con la idea de que, desde el principio, el personaje queda asociado precisamente a este sistema connotativo.

En ese sentido también se puede entender el uso que se hace de la distinción, heredada de la comedia latina, entre servus fallax y servus fidus. Pármeno desempeña, al principio de la comedia, el papel de servidor leal. Ahora bien, en la corte celestial, algunos ángeles son ante todo 'servidores'; forman la "casa," un "ejército del cielo" que está total y permanentemente a las órdenes del Todopoderoso. ${ }^{8} \mathrm{El}$ mismo Pármeno establece una relación entre su fidelidad, su lealtad y su inocencia. ${ }^{9}$ La convención teatral del servus fidus tiende así a orientarse de modo singular para adaptarse a las connotaciones asociadas al personaje.

Sin embargo, existe un aspecto mucho más importante del angelismo de Pármeno. Desde el principio, está dotado de facultades intelectuales fuera de lo común, lo que lo sitúa muy por encima de los demás. Así es como demuestra mucha perspicacia ante las verdaderas intenciones de Celestina y Sempronio. El anónimo autor ha querido manifestar esa superioridad intelectual en la escena en que Pármeno denuncia la farsa del diálogo fingido entre la vieja y el criado. ${ }^{10}$

En varias ocasiones, se opone esa facultad a la poca edad del personaje para recalcar la idea de que aquélla no es fruto de la experiencia sino más bien el resultado de una disposición natural. Dicho de otro modo, Pármeno destaca por su discreción natural, por su ingenium, ese buen natural que evoca Calixto hablando del mozo, al que considera como su mejor criado. ${ }^{11} \mathrm{~A}$ la inversa, Pármeno confiesa a Celestina que, si no se lleva bien con Sempronio, es ante todo por la necedad y los malos modales de éste. ${ }^{12}$ Todo contribuye, pues, a hacer de Pármeno un dechado de inteligencia, de razón, capaz de medirse con 
Celestina a pesar del arsenal retórico de la vieja. La famosa escena 10 del auto 1 , primera refriega entre los dos personajes, ilustra el combate entre las dos formas de saber sobre las que se estuvo debatiendo durante el siglo XV: $:^{13}$ la sabiduría fruto de la experiencia, encarnada por Celestina "concepto puramente medieval, como el que hallamos en Juan Manuel"14 y la discreción natural, más propia del pensamiento humanista. Ese primer duelo permite a la alcahueta percatarse de que no podrá vencer a alguien como Pármeno por el espíritu, sino por el cuerpo: en efecto, intelectualmente, el joven es a todas luces invulnerable.

Por su espíritu, Pármeno es semejante a los ángeles, criaturas dotadas de una inteligencia superior, a mitad de camino entre la sabiduría de Dios y la de los hombres, como lo repiten constantemente los autores medievales. ${ }^{15}$ Esa comparación "semejante a los ángeles" se aplica a menudo, en los textos medievales, a filósofos y teólogos. Pues bien, en Celestina, es por medio del discurso filosófico como se procura significar la discreción casi sobrenatural de Pármeno. Éste habla como un verdadero filósofo, hasta tal punto que Celestina, finalizado un muy escolástico parlamento del mozo, exclama: " $\mathrm{O}$ malvado! ¡Como que no se te entiende! (254). Otros pasajes completan esa imagen de un Pármeno filósofo, semejante a los ángeles por el espíritu, como el topos de la -... mansa pobreza (259) que recuerda a Horacio, acaso de mano de Juan de Mena, pero también algunas ideas muy manejadas en la Facultad de Artes de Salamanca, a raíz de la docencia de Alfonso de Madrigal, el Tostado.

El caso es que ese "divino" Pármeno, ángel de la escolástica, tiene a quien parecerse. Resulta algo sorprendente que inmediatamente después de su achaque de aristotelismo agudo que provoca la perplejidad de la vieja, el joven proclame la identidad de su padre. Éste se llama Alberto. Tan germánico nombre no deja de sorprender en la Castilla del siglo XV. En un contexto universitario como el de Celestina, no puede por menos de remitir a dos célebres filósofos: Alberto de Sajonia (siglo XIV) y, sobre todo, Alberto el Grande, cuyas facultades intelectuales, absolutamente fuera de lo común, apabullaron a sus contemporáneos. Detengámonos en un pasaje en que Celestina establece hondas similitudes entre Pármeno y ese famoso Alberto: "gózome [...] que ayas [...] respondido al reconocimiento, discreción y engenio sotil de tu padre" (264). ¿Por qué insiste tanto en esos tres términos, casi sinónimos, si no es para orientar al personaje hacia la figura del gran filósofo? Las palabras siguientes de la vieja alcahueta bien podrían ser un guiño humorístico dirigido a un público de universitarios, con esa alusión a los "duros propósitos" de Alberto y la ulterior vuelta a la verdad ("lo cierto"), propósitos enigmáticos para nosotros, desconocedores de los pormenores biográficos del padre de Pármeno, pero que, en otro sentido, podrían tal vez esconder una solapada e irónica alusión a la biografía del otro Alberto, el Magno, concretamente a la cuestión del racionalismo heterodoxo. 
El antecedente filosófico de Pármeno podría incluso resultar confirmado por el nombre de su madre: Claudina sugeriría, asociado a Alberto, el nombre del filósofo Claudio Mamerto (Claudianus Mamertus, nacido ca 420), para algunos el mayor erudito de su siglo, al que los universitarios de la Edad Media concocían gracias a Abelardo y Alain de Lille. ${ }^{16}$ La cuestión de los nombres, en una obra como Celestina que gusta de los nombres significativos de la comœdia, no es ni mucho menos mera anécdota, como lo demuestra de sobra la complejidad de los valores semánticos del nombre Celestina. En el caso de Pármeno, es tanto más importante cuanto que se trata del único personaje de cuyos parientes se conoce la identidad. ${ }^{17}$ Ahora bien, como se verá más adelante, la caída de nuestro ángel se origina en un cambio de los significados connotados por sus genitores.

La configuración inicial del personaje Pármeno es la de un ser aparentemente modélico, entregado en cuerpo y alma a su amo, que le corresponde considerándolo como el mejor y "príncipe" de sus criados. Pármeno se confunde simbólicamente con el ángel, ${ }^{18}$ incluso con el primero de ellos, el "ángel de luz," es decir, el más hermoso, el más fuerte y el más perfecto: Lucifer. En la semántica de la caída angelical, era imprescindible dotar a un personaje de esos atributos superlativos. La caída de Pármeno, según el modelo semántico del ángel, sólo resulta significativa si se le presenta como el mejor, tanto en el plano de sus facultades como en el de la acción. En efecto, sólo el más fuerte, Lucifer o Pármeno, puede rebelarse contra el Amo.

Se tiende a limitar la caída de Pármeno únicamente a la corrupcion ejercida por Celestina, a considerarla como el mero resultado de la tentación carnal. Me parece que se trata de una explicación algo superficial, incapaz de dar cuenta de la complejidad del personaje y que, sobre todo, no permite entender por qué su ?conversión? es hasta tal punto radical y fatal. Tal como el personaje ha sido inicialmente configurado, el descubrimiento de la sexualidad es algo más que un anodino desasnamiento. Es un acto por el que su buen natural queda hondamente alterado. Además, la crítica olvida a veces de que la ocasión brindada por Celestina no es el único elemento que determine la desviación de Pármeno. Existe otro hecho de importancia por lo menos equivalente.

Para entender bien las desviaciones súbitas de Pármeno con relación a su comportamiento inicial, hay que considerar no sólo el hecho de que sucumba a la tentación de la carne sino también y sobre todo lo que se puede llamar una verdadera rebelión contra su amo. Ahora bien, dentro de lo que sabemos acerca de la caída de los ángeles, sólo existen dos principios que explican esa caída: la envidia y el orgullo, por un lado; el pecado de la carne, por otro lado. Se trata exactamente de las etapas fundamentales de la conversión del personaje de Pármeno.

El primer principio explicativo de la caída angelical está basado en la 
idea de rebelión. Algunos ángeles, y particularmente entre ellos el mejor, Lucifer, se rebelan contra la autoridad de Dios y deciden librarse del yugo de su Creador. ¿Por qué motivo? Según la tradición cristiana, la rebelión de Satán a la cabeza de los ángeles se debe a la envidia. Pero, eenvidia de qué? No todos los textos patrísticos concuerdan al respecto. Para algunos, como Gregorio de Nisa, los ángeles protestan y se rebelan porque el hombre fue creado con barro. ${ }^{19}$ Generalmente, la envidia de los ángeles tiene que ver con el hombre. Para san Ireneo, sólo esa envidia hacia el hombre puede ser el punto de partida de la insurrección. Tertuliano (en el De Patientia) acepta esa explicación, sugiriendo el sufrimiendo y la cólera del más hermoso y perfecto de los ángeles abandonado por su Creador cuando Éste creó al hombre a su semejanza. Lactancio, en el siglo IV, saca todas las consecuencias lógicas de ese principio explicativo: el futuro diablo es nada menos que el hermano menor de Cristo. Siendo el menor, recibe una impronta divina algo atenuada, así que queda ensuciado por el veneno de la envidia, mientras el mayor sabe permanecer al lado del Padre, unido a Él. Sabe además cómo merecerse su afecto. ${ }^{20}$ En el siglo XVI, el dominico Ambrosio Cantarino propone una explicación semejante: al considerarse como criatura perfecta, Lucifer quería que le eligiera Dios para ser la encarnación del Verbo. Por eso habría pasado de la decepción a la indignación, y de ésta al odio y a la rebelión. ${ }^{21}$

No es necesario recordar la importancia, en los textos bíblicos, del tema del odio entre hermanos (Abel y Caín, Amón y Absalón, etc.). En Celestina, a los dos criados, Sempronio y Pármeno, se les presenta a menudo como hermanos, de acuerdo con la imagen tradicional de los criados de la casa noble. A diferencia de Pármeno, Sempronio, por ser mayor, es más acabado como hombre. Lo dice la propia Celestina: "Mira a Sempronio: yo le fize hombre. Querría que fuéssedes como hermanos" (359). El conflicto inicial entre Sempronio y Pármeno tiene, pues, todas las apariencias de una rivalidad entre hermanos. Pero es Calixto, el Amo (el que, en la casa tradicional, desempeña el papel de pater familias) quien exacerba esa rivalidad. $\mathrm{Si}$, al principio, intenta calmar la posible envidia de Pármeno ("si para él hovo jubón, para ti no faltará sayo," 247), cuando los consejos de este último contradicen en exceso sus intereses, Calixto el insensato perdiendo el sentido de la equidad, opone a los criados para alabar a Sempronio y criticar a Pármeno, quien hasta entonces se consideraba el sirviente modélico:

Quanto remedio Sempronio acarrea con sus pies, tanto apartas tú con tu lengua, con tus vanas palabras. Fingiéndote fiel, eres un terrón de lisonja, bote de malicias, el mismo mesón y aposentamiento de la embidia. (275)

Lo injusto de los reproches de Calixto es excesivo, lo que provoca la rebelión del criado: 
Por ser leal, padezco mal. Otros se ganan por malos; yo me pierdo por bueno. El mundo es tal. Quiero yrme al hilo de la gente, pues a los traydores llaman discretos, a los fieles, nescios. (277).

$\mathrm{Al}$ oír las injustas palabras de su amo, Pármeno descubre un mundo trastornado. La idea de desviación está pues presente en el mundo mismo. No hay más remedio que dejarse llevar, ya que el amo no reconoce el valor de su sirviente. Ésta es la verdadera causa inmediata de la caída de Pármeno. A partir de ese punto, empieza a reprocharse a sí mismo el hecho de no seguir los consejos de Celestina ("si yo creyera a Celestina, no me maltratara Calisto," 277), y a decidir también ya no servir a su amo como antes: "nunca más perro al molino" (278). Ese profundo desengaño no deja de recordar el que sufrió Lucifer: el lema del ángel perfecto en el momento de su rebelión es non serviam, "ya no serviré."22

La rebelión luciferiana de Pármeno prepara su propia caída y, de hecho, en adelante, su papel será el de un sublevado, no sólo contra su amo sino también contra Celestina, como lo prueban los apartes del auto VI. Pero para que esa desviación sea definitiva, le queda a Pármeno tener que satisfacer otra forma de caída de los ángeles. Ésta nos lleva a la tradición judía y folklórica. ${ }^{23}$ La lectura de un episodio del Génesis ha dado lugar al establecimiento de una teoría muy atractiva sobre la caída de los ángeles: "Viendo los hijos de Dios que las hijas de los hombres eran hermosas, tomaron para sí mujeres, escogiendo entre todas" (Gn. 6:2). Esos "hijos de Dios" son los ángeles, como lo decía explícitamente la antigua versión griega ("los ángeles de Dios"24). El Libro de Enoch ${ }^{25}$ pone directamente en relación esa atracción sexual de los ángeles por "las hijas de los hombres" y su rebelión. Según Hénoch, es únicamente ese deseo el que anima a doscientos ángeles a abandonar el Cielo para unirse con las mortales.

Recordemos que esos ángeles ofrecieron a sus amadas algunos de sus poderes, como la brujería y el arte de seducir. A los otros mortales (los hombres) les enseñaron el arte de la guerra. Fácil resulta imaginar el desorden que se originó en ello, y se entiende la necesidad del Diluvio universal, tanto más cuanto que los hijos de los ángeles lúbricos, los Nephilim, unos temibles gigantes, lo destruían todo. El Nuevo Testamento y la tradición cristiana son más reservados acerca del pecado carnal de los ángeles. La gran dificultad que provoca semejante explicación es, en efecto, la de la naturaleza espiritual del ángel. ¿Cómo concebir la tentación de la carne sin corpus delicti? Una interesante solución se encuentra en las Homelías del Seudo-Clementín. Los ángeles, viendo que los hombres ensuciaban la Creación, pidieron a Dios permiso para tomar una forma carnal con el fin de bajar hasta la tierra y poner orden. Pero, nada más verse dotados de un cuerpo y observar la belleza de las "mochachas," como diría Pármeno, empezaron a sentir un deseo insoportable que les hizo olvidar por completo el objeto de su misión. ${ }^{26}$ 
Como ya he apuntado, la tentación de la carne es la única arma eficaz de Celestina para con Pármeno; la vieja alcahueta ha sabido muy pronto medir la amplitud de los deseos lúbricos en ese adolescente, que permanece aún en "estado de inocencia." La escena en la que Celestina se las apaña para que Pármeno, como los ángeles, tome por mujer a una de esas "hijas de los hombres," Areúsa, es capital: ${ }^{27}$ se trata del punto culminante y definitivo de la conversión del personaje. Nótese con qué esmero Rojas ha dotado esa escena de un doble simbolismo, de extraordinaria fuerza, para significar la caída del personaje. Antes de ser un episodio erótico-burlesco que llama la atención por el voyeurisme de Celestina, la escena está concebida como una parodia de ceremonia nupcial planeada por la ministra del diablo que es Celestina. Ella es, en efecto, quien pide a Pármeno las ?palabras de presente? ("Sí, prometo," 379), antes de incitar al joven a que consuma la unión, introduciéndole en la cama de Areúsa. Ese simbolismo nupcial se mantiene, por otra parte, a lo largo del auto IX, con la comida en casa de la vieja, organizada por Pármeno y "pagada" por Calixto (que pasa a ser "padrino" sin saberlo), comida que se asemeja a unas bodas antes de transformarse en orgía.

Claro está que esa ceremonia resulta pervertida de cabo a rabo, ya que el joven se compromete no con Areúsa sino con Celestina. En esa traslación se halla la clave del otro significado simbólico de la escena. Con esa falsa ceremonia nupcial se concluye de hecho un pacto con Celestina que equivale a un pacto diabólico. El texto sugiere veladamente la asociación entre Celestina y el diablo, en la situación presente, con el aforismo "al hombre vergonzoso el diablo le traxo a palacio" (378). En consecuencia, la promesa de Pármeno es crucial, sobre todo teniendo en cuenta la diabólica reacción de Celestina: “ $\mathrm{iHa}$, don ruyn! Palabra te tengo! A buen tiempo te así"(379). Si se piensa que la expresión más frecuente en los antiguos pactos con el diablo es "yo prometo" ("Prometo al gran Lucifugio" ${ }^{28}$ ), la connotación debía ser clara para los primeros lectores de Celestina. La prueba está en que Rojas prefirió suprimir esas frases, tal vez por excesivamente atrevidas, en el paso de la Comedia a la Tragicomedia. En esa escena, en la que Párméno hace un pacto con la clientula del diablo para obtener la satisfacción inmediata de su deseo, es donde el ángel se transforma definitivamente en diablo.

En cuanto se rebela contra su amo, podemos constatar en Pármeno una desviación fundamental en su conducta. Los críticos se han equivocado, a mi parecer, cuando han visto en ese cambio de actitud la adhesión del personaje a la causa celestiniana. El Pármeno que se rebela no defiende ninguna causa salvo la suya: se siente tan libre de criticar a Calixto como a Celestina. Por eso hay que ver sin duda en ese cambio el inicio de una progresiva satanización del personaje, que se hará definitiva después del "pacto" del auto VII. ¿Por qué satanización? Porque le corresponde de aquí en adelante a Pármeno desempeñar el papel de la crítica, de la malicia, de la murmuración. En suma, Pármeno pasa 
a ser poco a poco el "denunciador," el "adversario," dos posibles traducciones del nombre de Satanás. Se hace progresivamente diablo, diabolos, (el que divide); retomando las palabras de Mateo, es "el enemigo que sembró cizaña entre el trigo" (Mt 13, 25), ${ }^{29}$ lo que nos recuerda el papel que juega el ángel exterminador, o ángel de la muerte, en la literatura rabínica. ${ }^{30}$

Hay que insistir en este punto porque, efectivamente, puede sorprender tamaño cambio si nos acordamos de la bondad angelical de Pármeno al principio de la obra. Le sorprende al mismo Pármeno, ya que exclama "no soy el que solía" (361), pero, en el famoso diálogo cruzado del auto VI, también sorprende a Sempronio que pensaba encontrar en Pármeno a un nuevo aliado (" $i$ Toda esta es la amistad que con Celestina y comigo havías concertado? ¡Vete de aquí a la mala ventura!," 339). Pármeno no cesa de criticar a sus dos interlocutores con una rabia y hasta un odio sorprendentes. Sempronio no se equivoca cuando exclama, harto ya: " $\mathrm{O}$ mal fuego te abrase! Que tú fablas en daño de todos; $; \mathrm{O}$ intolerable pestilencia mortal te consuma, rixoso, embidioso, maldito!" (338).

Podría pensarse que, después de los pactos del auto VII y del banquete simbólico del IX, Pármeno había terminado por abrazar la causa de la alcahueta y de su compañero. A primera vista, Sempronio y Pármeno tendrían que ser ya como hermanos y algunos críticos han insistido en el hecho de que, en este punto, son casi intercambiables. El problema es que estas suposiciones no son del todo exactas. Pármeno no se confunde con Sempronio salvo en la cobardía rufianesca de que hacen gala en la salida nocturna. Esa nueva etapa sirve para evidenciar la tradicional idea de un diablo que "mora entre nosotros." La víctima elegida es, indirectamente, Sempronio. El objeto de la nueva hermandad entre Pármeno y Sempronio consiste en mostrar hasta qué punto el espíritu diabólico (espíritu de división) puede destruir cualquier alianza, en este caso la que se ha formado entre Celestina y Sempronio. Como en el auto VI, Pármeno ya no se caracteriza más que por la maldad. Más que nunca es el adversario, el acusador el tentador. Cuando Calixto ofrece a Celestina una cadena de oro (auto XI, 3), Pármeno murmura de nuevo contra la alcahueta. En ese momento Sempronio es aún capaz de salir en defensa de la vieja, de justificarla: "en mi alma todo lo merece y más que le diese" (448). Sistemáticamente, Rojas va a colocar en boca de Pármeno la murmuración y la sospecha, incluso tratándose de Melibea (cf. 450), hasta el extremo de hacer que Sempronio cambie de parecer acerca de Celestina y deje de defenderla:

Pármeno: No se halla digna de tal don, tan poco como Calisto de Melibea.

Sempronio: ?Qué quieres que haga una puta alcahueta.? (452)

Ese cambio de actitud incluye la primera alusión al desenlace trágico, que no carece de ironía en la formulación: "guárdese del diablo, que sobre el 
partir no le saquemos el alma" (453). En efecto, a fin de cuentas, lo esencial de esa diabolización reside justamente en el hecho de llevar la acción hasta su desenlace fatal; en el hecho de que ese nuevo diablo de Pármeno sea capaz de influir en Sempronio hasta hacer de él un asesino. ${ }^{31}$ Cuando los criados llaman a la puerta de Celestina para exigir de ella su parte del botín, Pármeno hace todo lo posible para incitar a Sempronio a que cometa el asesinato. El joven criado está "tan fiero" que Celestina queda "espantada" (477); no deja de preconizar la interrupción de las negociaciones y sugiere el paso a la acción (481); por fin, él es quien sugiere el asesinato, siendo el primero en amenazar de muerte a Celestina: "embiarte he con nuevas a ella [i.e. la difunta madre de Pármeno] donde mejor te puedas quexar" (483). En el momento en que Sempronio desenvaina y empieza a herir a Celestina, Pármeno le alienta, exclamando: “¡Dale, dale, acábala! [...] ¡Muera, muera!? (485).

La desviación de Pármeno provoca también el de su compañero, hasta el asesinato y la muerte. La inspiración diabólica de semejante comportamiento la avala, por otro lado, toda una tradición literaria en la que el diablo, sus ayudantes y demás intermediarios están entre los hombres para sembrar la cizaña y provocar asesinatos. Recordemos el exemplum 42 del Conde Lucanor en el que la Falsa Beguina rivaliza en maldad con el diablo y provoca una matanza en la aldea.

El simbolismo del ángel caído, transformado en diablo, alumbra la desviación máxima del personaje de Pármeno entre el auto I y el XII. Pero, ¿̨o habría que desplazar algo la problemática de la diabolización del personaje? ¿En qué reside verdaderamente la desviación de Pármeno: en su diabolización o, más bien, en su angelización inicial? Desde el principio, abundan las desviaciones de Pármeno con relación a la imagen que pretende dar de sí mismo. El servus fidus es una convención literaria pero también una postura adoptada por el personaje que presenta algunos fallos: acepta la hipocresía, por ejemplo cuando Celestina le habla de la eventualidad de un amorío (cf. 261) y cede a veces a esa murmuración y a ese egoísmo que le caracterizarán luego (“ ¿Ya las lloras [las cien monedas]? [...] ¡En casa se havrá de ayunar estas franquezas!" [273]).

Acaso para comprender esas grietas en la construcción del personaje inicial debamos preguntarnos: ¿quién es Pármeno? ¿Podía realmente ser un personaje angelical? Pármeno es un personaje marcado por sus orígenes, lo que explica sin duda el hecho de que sea el personaje del que disponemos de más datos biográficos. Y si se cree "bueno," pareciéndonos angelical, tal vez sea porque no lo sabe todo de su ascendencia. De su padre sólo conoce el nombre y tiene una idea totalmente falsa de su madre y de las razones por las que lo dejó en casa de Celestina. ${ }^{32}$ Volvamos a los nombres de sus padres, ya que los significados que connotan son absolutamente reversibles. Según una tradición popular que perduraría hasta el siglo XIX, Alberto Magno pasaba por ser autor de toda clase 
de libros secretos: desde tratados de ginecología (como los Secretos de las dueñas) hasta obras de alquimia, de magia y brujería. Se le atribuía la mayor parte de los grimorios usados por los brujos en sus invocaciones y maleficios. 'Alberto' alude, por consiguiente, tanto a la hechicería como a la brujería, que resultan ser justamente las actividades principales de Claudina, madre de Pármeno.

En semejante universo, lo diabólico no queda lógicamente muy lejos y, en ese caso también, el nombre de 'Alberto' resulta rico de significado. En la prosa caballeresca castellana, tanto la autóctona como la adapatada de la literatura francesa, 'Roberto' o 'Alberto'son dos nombres que designan seres marcados por lo diabólico. Citaré aquí sólo dos ejemplos para ilustrar ambos nombres: la Historia de Roberto Diablo, traducción del célebre roman picardo y, sobre todo, el caso de un personaje mencionado al final del relato corto interpolado en el Libro del Caballero Zifar, la historia del "Caballero atrevido." Se trata de ese intrépido caballero que se introduce en un lago mágico y se casa con la reina de esos lugares, dama muy hermosa en apariencia, de la que nos enteramos al final de que es "la señora de la Trayçión," un diablo horroroso. Ahora bien, en esa especie de país de jauja donde todo crece con la mayor celeridad, en pocos días el fruto de los amores del héroe y su dama del lago es un mozo, que sufrirá el exilio con su padre. Ya fuera del lago, el caballero vuelve con los suyos que no pueden reprimir su sorpresa al enterarse de que su amo ha tenido, en tan poco tiempo, un hijo ya mayor que él. El caballero duda mucho de la suerte de su hijo, teniendo en cuenta el carácter diabólico de su madre:

E bien creo que de parte de su madre que es fijo del diablo e quiera Dios que recuda a bien lo que non puedo creer, ca toda criatura torna a su natura. ${ }^{33}$

A consecuencia de ello, todos deciden proceder al bautismo inmediato de su hijo, y el caballero no duda ni un momento en el nombre que le dará:

Çierto, dixo el cavallero, non lo sé sy agora non lo bautizamos e le pongamos nonbre de nuevo e tengo que será bueno que lo fagamos. $\mathrm{E}$ acordaron de lo bautizar e pusiéronle nonbre Alberto Diablo. ${ }^{34}$

El nombre Claudina podría también aludir a ese universo de significado por medio del poeta latino Claudiano (Claudius Claudianus, siglo Iv), autor del Rapto de Proserpina, uno de los mejores ejemplos, en el siglo IV, de literatura órfica, en la que aparece, precisamente, el "triste Plutón" que Rojas pide prestado a Mena para el conjuro de Celestina. ${ }^{35}$

La descripción que hace Celestina (cf. 364 y siguientes) de las actividades de Claudina no deja ningún lugar a dudas: se trata de una bruja a la que teme el mismo diablo. Descendiente de brujos, Pármeno está claramente marcado por 
la infamia, desde el momento en que nació, como lo muestra Celestina que no duda en aludir a la influencia de los padres en el mozo: "tienes a quien parezcas" (369), le lanza con cierta malicia. "Toda criatura torna a su natura," como diría el Caballero Atrevido. Pero la infamia se encuentra también del lado de su criança. Como se sabe, es su "madrina" ${ }^{36}$ Celestina, "puta vieja" hechicera quien además lo crió. Pármeno ha nacido, pues, y crecido dentro de un universo diabólico. Estas marcas de infamia se hallan confirmadas por una vida errante y vagabunda que incluso Celestina le echa en cara, ${ }^{37}$ acrecentada, como lo subrayó Marcel Bataillon, por nueve años de servicio con los frailes de Guadalupe. ${ }^{38}$

Además, el cuerpo del mozo presenta aspectos que aluden a signos diabólicos. La graciosa referencia a su ardor sexual por Celestina sugiere la lubricidad del espíritu demoníaco; pero, sobre todo, la réplica de Pármeno, al asimilar su sexo a la "cola de alacrán," remite claramente a lo diabólico. El escorpión, en efecto, "se coloca a menudo entre las bestias demoníacas," del mismo modo que, como signo del zodíaco, hace referencia al ocultismo y la diablura ${ }^{39}$. El digno hijo de Claudina y de Alberto sólo podía tener un sexo "como cola de alacrán."

La primera desviación de Pármeno no es su caída en el mal sino más bien el hecho de haber querido huir de una inclinación al mal tanto nata como adquirida. Su comportamiento no hace más que devolverle ineluctablemente a su infamia original. ${ }^{40} \mathrm{De}$ ahí que semejante análisis de la trayectoria del personaje nos alumbre quizás sobre la significación global de la caída en Celestina: jacaso Rojas nos habla del paso del orden al desorden, a un desorden creciente que culmina con la muerte? $\mathrm{O}$, al contrario, jacaso denuncia un desorden inicial, estructural, a consecuencia del cual resulta posible, por medio de la "caída" moral y su castigo, un regreso al orden? ${ }^{41}$

\section{NOTAS}

1 Este artículo es traducción de la ponencia que presenté en el coloquio L'Écart: notion et manifestations, organizado por A. Redondo en la Sorbona en marzo de 1998, con el título "Les écarts de Pármeno: la chute d'un ange." Al parecer, la publicación de las actas de dicho coloquio ha quedado suspendida, lo que me ha conducido a publicar en esta revista una traducción española del mencionado trabajo. Por otro lado, mil gracias a Michel Garcia por lo que él sabe.

2 "[...] una estructura muy trabada, en la que el personaje determina la acción, la acción transforma al personaje y un inexorable encadenamiento de causas lo gobierna todo" (DEYermond, 1980:486).

3 RUSSELL, 1991:77.

4 "The Devil and the other demons are spiritual or angelic creatures cre- 
ated by God in a state of innocence, and that they became evil by their own act" (KENT, 1913a:1/7).

5 En Celestina se leen algunas ocurrencias de la palabra con el significado criado, pero resulta significativo apuntar que dicho término, aplicado a Pármeno, tiene casi sistemáticamente el significado de 'joven,' 'adolescente.' Cf. Russell, 1991:92. Tomemos nota de expresiones como: "Avnque soy moço, cosas he visto asaz," "no [...] me tengas, avnque moço, por insipiente," "tu mucho eres moço," pertenecientes todas al primer auto. Para un análisis de todas las ocurrencias de la palabra, se puede consultar la reciente edición electrónica del texto: cf. GARCI-GÓMEZ.

6 Celestina, I, 10, p. 253. Todas nuestras referencias al texto remiten a la edición de RuSSELL, 1991.

7 BIEDERMANN, 1996:35.

8 CHEVAlIER / GHEERBRANT, 1982:45; GÉRARd, $1989: 76$ y GoNZALO Rubio, 1977 quien señala que, en la literatura rabínica algunos ángeles se llaman "ángeles servidores" (1977:19 y 31). Del mismo modo, en el Talmud (relato de Sanh. 93a) se dice que Adán, en el jardín del Edén, era servido por ángeles que le preparaban de beber y comer (1977:49). En el Corán, los ángeles aparecen también como los servidores de Dios (1977:97). Para un estudio profundizado aunque general de la angelología, véase Vacant / Mangenot, 1903-1950, s.v. "Ange" y el Dict. Encyclop. de la Bible, 1987, s.v. "Ange."

9 Celestina, I, 8, p. 249

10 Celestina, I, 8, pp. 248-249.

11 Celestina, I, 7, p. 248.

12 "Con vanos consejos y necias razones de aquel bruto Sempronio..." ( 254).

13 Cf. Rodríguez Velasco, 1993 y 1993-95.

$14 \mathrm{El}$ ejemplo \#2 del Conde Lucanor ilustra precisamente esa oposición pues el "hijo" encarna la discreción natural y el "padre" esa sabiduría adquirida con las enseñanzas y escarmientos de la experiencia.

15 Podemos aludir, entre muchos otros ejemplos, a la escala de los seres según Ramón Llull, pero también a Yehuda ha Levi quien afirma, en su tratado Cuzari, que los ángeles son inteligencias puras, entendimientos en acción: perciben la esencia de las cosas en sí mismas, ahorrándose, por consiguiente, los accidentes. Éste es también el parecer de santo Tomás en sus famosas quaestiones sobre los ángeles de la Summa Teológica (I, qu. L-LXII y qu. CVI-CXIv); GonZAlO RuBIO, 1977: 67.

16 Gran filósofo y orador elogiado por sus contemporáneos, Claudiano Mamerto se hizo célebre gracias a un tratado filosófico redactado hacia 470 contra las teorías de Fausto de Riez sobre la naturaleza material del alma. En el $D e$ statu animae, Claudiano defiende la no-corporeidad del alma en nombre de un espiritualismo a ultranza inspirado del platonismo, del neo-platonismo y del neo-pitagorismo. Cf. Dictionnaire encyclopédique du christianisme ancien, 1983:497 y Bibliotheca sanctorum, 1967. 
$17 \mathrm{El}$ caso de Melibea es distinto ya que sus padres son, al mismo tiempo, personajes actantes.

18 Otro elemento podría servir para connotar esa figura angelical. Se encuentra en un curioso pasaje de la primera entrevista entre Pármeno y Celestina en la que el tema del llorar se repite, bajo varias formas derivadas, nada menos que nueve veces en nueve líneas (Celestina, I, 10, p. 254). Ahora bien, la lamentación de los ángeles es un tema recurrente en la literatura talmúdica (GonZAlo RuBIO, 1977, p. 45) antes de ser un motivo iconográfico muy corriente en el arte medieval, especialmente en Italia.

19 Ésta es también la explicación de la rebelión de los ángeles en el Corán: el ángel "Iblis se rebela cuando se le ordena hacer pleito homenaje al hombre, al considerarse (por haber sido concebido a partir del fuego [cf. también el Libro de Enoch]) como superior a un ser formado de arcilla. Cf. GonZalo Rubio, 1977:99.

20 "Dios, antes de crear el mundo, produjo un espíritu semejante a sí mismo, repleto de las virtudes del Padre. Luego, hizo otro en el que la impronta del divino origen quedó borrada, al ser ensuciado por el veneno de la envidia, lo que le hizo pasar del Bien al Mal [...] Tuvo celos de su hermano mayor, el cual, siempre unido al Padre, tenía asegurado su afecto. Aquel ser que de bueno se hizo malo es llamado diablo por los Griegos" (Lactancio, Divinae Institutiones, II, 9, citado por VILLENEUVE, 1972: 13 [en traducción nuestra]).

21 Cf. A. Catarino, De Gloria bonorum angelorum y lapsu malorum, citado por Romi, 1968:16. Desde una misma perspectiva, Suárez asentará la rebelión de Lucifer en la revelación del modo en que se llevaría a cabo la Encarnación del Verbo. Cf. De Angelis, VII, XIII, citado por Kent, 1913a.

22 Cf. VILLENEUVE, 1972:13. No me detengo en la explicación de la rebelión de los ángeles por el pecado de orgullo que resulta menos ilustrativa en cuanto a Pármeno. Es la tesis más ortodoxa, seguida por Orígenes, Eusebio, Hilario, Ambrosio, Jerónimo, Agustín y Tomás. El orgullo hubiera consistido en hacerse igual o, por lo menos, semejante a Dios, en querer, por consiguiente, reinar sobre la mitad del cielo. Sobre la explicación proporcionada por santo Tomás, véase Summa theologica, I, qu. 63, art. 7. Para el Seudo-Dionisio, la rebelión de Lucifer se debe sólo a la pura malicia.

23 Cf OsTY, 1973, nota a Gn, 6, 2 y Gonzalo Rubio, 1977:19: “[la unión carnal de los ángeles] cuya índole folklórica está actualmente, al parecer, fuera de duda." Señalemos, con todo, que el tema de la caída de los ángeles no aparece en el Talmud (GoNZALO RUBIO, 1977:40 y especialmente 50). La aparición de ese tema sirve para explicar el origen del principio del mal ya que éste no existía como tal en la teología hebraica (a diferencia de las creencias persas que postulaban la existencia de un principio activo y personificado del mal: Ariman). Cf. GonZalo Rubio, 1977:31.

24 Cf. KeNT, 1913b.

25 Le livre hébreu d'Hénoch, 1989. Otra ed., VaIllant, 1976. El Libro de Enoch es el más importante de los numerosos libros que forman lo que se llama 
"la literatura apocalíptica" judía (del siglo II. a. C. al II d. C.), que mantiene una relación estrecha con los libros proféticos del Antiguo Testamento. Cf. Gonzalo RuBIO, 1977:26.

26 Cf. KeNT, 1913b.

27 Véase mi análisis de esta escena en Heusch, 2001.

28 ROMI, 1968:46.

29 "Celui qui divise, particulièrement por la médisance ou la calomnie, souvent la haine y l'envie.” Cf. GÉRARD, 1989.

30 Cf. Gonzalo Rubio, 1977: 22.

31 " [...] la función que desempeña con mayor frecuencia el príncipe de los demonios es la de provocar la muerte" (GonZalo RuBio, 1977:54). En la tradición talmúdica ese espíritu demoníaco es Duma, el ángel de la muerte.

32 "Mi madre, muger pobre, morava en su vezindad; la qual rogada por esta Celestina, me dio a ella por sirviente" (241).

$33 \mathrm{He}$ editado ese relato interpolado del Zifar en $\mathrm{HeuscH}, 2000$. El pasaje citado se encuentra en la pág. 283.

$34 \mathrm{HeUSCH}, 2000: 283-284$.

35 De todos modos, como algunos lo han hecho notar, el nombre está connotado negativamente por la referencia implícita al verbo claudicare y al adjectivo claudus: cojo, que anda mal, defectuoso. $Y$ como es sabido, "quien mal anda, mal acaba."

36 Pármeno dice de sus padres que son "compadre" y "comadre" de Celestina, lo que podría significar que ésta es madrina del mozo, según el significado de esos términos en la Castilla medieval.

37 "Porque has por tantas partes vagado y peregrinado que ni has avido provecho ni ganado debdo ni amistad" (256).

38 Cf. Bataillon, 1961:141, que cita un refrán recogido por Correas: "raro mozo de frailes sale bueno." Para Bataillon, Pármeno, al igual que Sempronio, es "vil de nacimiento" (142).

39 TONDRIAU / VilleneUve, 1968:203.

40 Esto no implica necesariamente un determinismo que anularía el libre albedrío, sino una "debilidad" del alma, que podría ser una de las características morales del personaje. Sin duda, un personaje que estuviera menos marcado por ese vicio de accidia hubiera podido superar, a fuerza de voluntad, esa nefasta influencia.

41 Agradezco a Zoraida Carandell sus sugestivas observaciones durante la discusión, además de sus sugerencias bibliográficas. 


\section{REFERENCIAS BibLIOGRÁFICAS}

BATAILLON M., 1961, "La Celestina" selon Fernando de Rojas, Paris: Didier. (LA) Brible, éd. d'É. Osty, 1973, Paris: Éd. du Seuil.

Bibliotheca Sanctorum, 1967. Rome: Instituto Giovanni XXIII.

BIEDERMANN H., 1996, Encyclopédie des symboles. Coll. La Pochothèque (Encyclopédies d'aujourd'hui), Paris: Le Livre de Poche.

CANAVAGGIO J., 1983, Introducción générale, Théâtre espagnol du XVt siècle, coll. La Pléiade, Paris: Gallimard.

CHEVALIER J. y GHEERBRANT A., 1982, Dictionnaire des symboles. Coll. Bouquins, Paris: R. Laffont.

DEYERMOND A., 1980, Historia y crítica de la literatura española (dir. por F. Rico), 1: Edad Media. Barcelona: Crítica.

Dictionnaire Encyclopédique de la Bible, 1987. Publ. par le Centre "Informatique et Bible" de l'Abbaye de Maredsous. Turnhout: Brepols.

Dictionnaire Encyclopédique du Christianisme ancien, 1983. Paris: Éd. du Cerf. GERARD A.-M., 1989, Dictionnaire de la Bible, Coll. Bouquins, Paris: R. Laffont. GARCI-GÓMEZ M., s.d., ed. interactiva, contexto, notas, bibliografía, concordancias y tesoro de La Celestina o tragicomedia de Calisto y Melibea de Fernando de Rojas, http://www.duke.edu/web/cibertextos .

GONZALO RUBIO C., 1977, La Angelología en la literatura rabínica y sefardí. Biblioteca Nueva Sefarad, II, Barcelona: Ameller Ediciones.

HEUSCH C., 2000, La Caballería castellana en la baja edad media. Montpellier: ETILAL - Université de Montpellier III.

, "Engagements et promesses dans La Célestine de Fernando de Rojas," dans

C. Raynaud (éd.), Serment, promesse et engagement: rituels et modalités (Actes du VIe Congrès du C.R.I.S.I.M.A., Montpellier, novembre 2001). Montpellier: Université Paul-Valéry.

KENT W.H., 1913a, "Devil," in The Catbolic Encyclopedia, The Encyclopedia Press, Inc. Electronic version: New Advent, 1996: http://www.knight.org/ advent.

KENT W.H., 1913b, "Demonology," in The Catholic Encyclopedia, The Encyclopedia Press, Inc. Electronic version: New Advent, 1996: http:// www.knight.org/advent.

Le Livre bébreu d?Hénoch ou Livre des palais, 1989, trad. y éd. par Charles Mopsik. Lagrasse: Verdier.

RODRÍGUEZ VELASCO J., 1993, "El descubrimiento de la discreción," Actas del Primer Congreso Anglo-hispano, Madrid: Castalia. , 1993-95, “¿Dante por boca de Pármeno? Opiniones, sectas y discreción," Estudios Románicos, vol. 8-9.

ROMI, 1968, Métamorphoses du diable, Paris: Hachette.

RUSSELL, P. E., 1991 (éd), F. de Rojas, Comedia o Tragicomedia de Calisto y Melibea. Madrid: Castalia. 
TONDRIAU, J. y VILLENEUVE, R., 1968, Dictionnaire du diable et de la démonologie, Paris: Marabout Université.

VAILLANT, A., 1976, éd. du Livre des secrets d?Hénoch, texte slave et traduction française. Paris: Institut d'Études Slaves.

VACANT, A. y MANGELOT, E., 1903-1950, dir., Dictionnaire de théologie catholique, Paris: Letouzey y Ane, 30 vol.

VILLENEUVE, R., 1972, L'univers diabolique, Albin Michel.

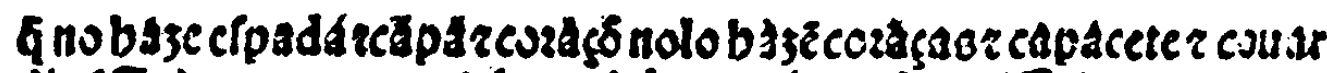

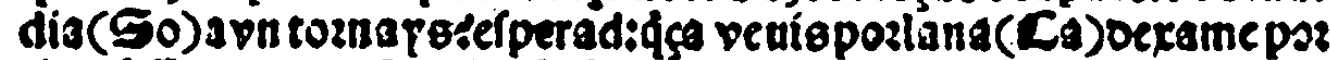
ó́os feĩoza à puefta efta cl efcala. ( 132 .) o defdicbada yo: $r$ como vas tan rezío z c5 tå ta pzieffa z oefarmado a meterte eatre quil no co

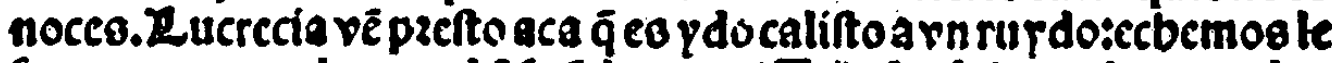

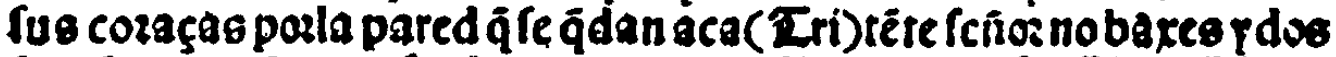

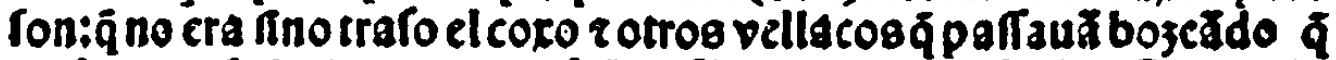
yafe tozna fora/tenteitente fefiozcólas manosal efcola(Ea) o vala

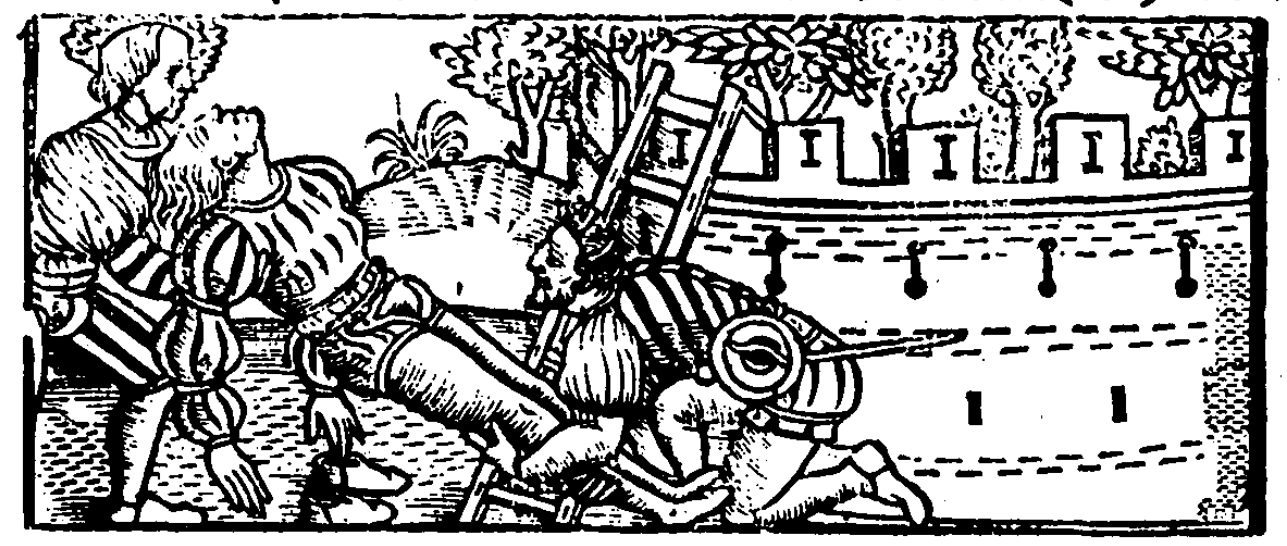

Auto XIX. Toledo, 1538. 